\title{
O COLECIONISMO BIBLIOGRÁFICO: UMA ABORDAGEM DO LIVRO PARA ALÉM DA INFORMAÇÃ̃O ${ }^{1}$ \\ COLLECTING BOOKS: UNDESTUNDING BOOKS OUT OF THE INFORMATION \\ $A P R O A C H$
}

\author{
Eduardo Ismael Murguia \\ Doutor em Educação \\ CID-USP / PPGCI-UNESP \\ murguia@usp.br
}

\begin{abstract}
Resumo
O presente artigo pretende refletir sobre um tema esquecido pela Biblioteconomia: a formação de coleções bibliográficas. Desde o inicio da Ciência da Informação, a ênfase foi colocada na informação, passando o suporte e a materialidade do livro a um segundo plano. Com a finalidade de iniciar uma discussão que resgate o suporte da informação, foi proposto o conceito de semióforo como meio de salvar a divisão material/imaterial. Assim, num primeiro momento apresenta-se uma discussão bibliográfica que introduz os conceitos de Cultura material e de Colecionismo em diferentes áreas. Em seguida, centraliza-se a argumentação no campo da Biblioteconomia, na sua relação com o colecionismo bibliográfico, destacando-se a Bibliofilia. Por último, na justificativa, resgata-se o título do trabalho para apontar a necessidade dos estudos de colecionismo na área, propondo-se a utilização do conceito de semióforo, não unicamente como ferramenta que supere a divisão suporte/texto, mas como um conceito que oferece subsídios teóricos para o entendimento do problema; para assim chegar ao objetivo específico da pesquisa: discutir que, na sua condição de semióforo, o objeto livro possui características específicas (subjetivas e materiais) que fazem com que o sujeito estabeleça relações outras do que a simples busca de informação e criação de conhecimento.
\end{abstract}

Palavras-chave: Coleções. Colecionismo Bibliográfico. Livros.

\section{INTRODUÇÃO}

Os estudos de coleções se configuram, na atualidade, como um vasto e fértil campo de estudo que têm contribuído com múltiplas áreas do conhecimento, oferecendo diversas abordagens e interpretações. Esses estudos são importantes porque nos colocam perante a evidência do mundo da cultura material e de seus objetos. Ademais, desvendam as obscuras relações que o sujeito estabelece com os objetos. Dentre esses objetos, notadamente, o livro merece especial

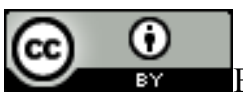
DOI 10.5007/1518-2924.2009v14nesp1p87

\footnotetext{
${ }^{1}$ Este texto, com ligeiras modificações, foi apresentado e publicado nos anais do VIII ENANCIB realizado na cidade de Salvador em outubro de 2007.

Enc. Bibli: R. Eletr. Bibliotecon. Ci. Inf., ISSN 1518-2924, Florianópolis n. esp., 1. sem. 2009.
} 
atenção pelas imbricações pessoais e culturais que apresenta sua posse, bem como pelas suas características essenciais de suporte e de informação. Nesse sentido, acreditamos que o colecionismo de livros vai além da informação, pois a sua apropriação material está permeada por motivos diversos, que não unicamente a criação do conhecimento.

No presente trabalho, pretendemos oferecer algumas considerações, chamando a atenção para a importância das coleções quando relacionadas aos livros - fim último da razão de ser das bibliotecas. Portanto, delimitamos nosso objeto explicitando que, embora a leitura seja a atividade relacional entre o indivíduo e o texto, ela não define um único tipo de relação. Da mesma forma, não entramos na discussão das mutações ocorridas na leitura e no texto com o advento das Novas Tecnologias da Informação, pois é justamente motivo de nosso interesse analisar o dispositivo material e seus efeitos recordatórios e simbólicos.

Pretendemos também iniciar uma discussão sobre um aspecto relegado pela Biblioteconomia: a formação de coleções. Assim sendo, esta apresentação prioriza as bibliotecas pessoais, embora não exclua - em alguns momentos - as bibliotecas de outros tipos.

O texto apresentado é uma reflexão teórica, fundamentada na bibliografia existente sobre os temas que articulam nossas preocupações. Ele é um ensaio de sistematização e análise sobre o colecionismo bibliográfico. Assim dividimos este artigo em três momentos: A Coleção e o Colecionismo; A Biblioteconomia e as Coleções Bibliográficas; e a Coleção de Livros: uma Questão Além da Informação.

\section{A COLEÇÃO E O COLECIONISMO}

Os objetos existem porque eles respondem à necessidade do ser humano de poder agir na natureza. Eles respondem sempre a um vazio prévio, a algo que deva ser preenchido e aparecem quando a potência das capacidades humanas é vencida. Daí que também sejam vistos como alongamentos das faculdades do homem, quando não de próteses.

Para um entendimento mais sutil dos objetos devemos inseri-los num contexto maior que seria a cultura material. Para Bucaille e Pesez (1989), o conceito de cultura material supõe quatro aspectos: seu anonimato, sua permanência, sua inserção na infra-estrutura social ligada às técnicas e tecnologias, e o objeto. Este último aspecto, o objeto, é destacado como a condição sem a qual não existiria a cultura material. Os referidos autores assinalam também como a 
Antropologia e a História priorizam os elementos e características físicas do objeto; enquanto que outras áreas, como a Psicologia, enfatizam a relação de ordem subjetiva que o sujeito estabelece com o objeto.

E continuam destacando que a cultura material possui um elemento temporal que faz com que seja aparentemente permanente: as mudanças são lentas e não são facilmente perceptíveis. Ela também existe num espaço ou lugar específico, diferenciando uma cultura da outra; e apresenta elementos culturais na medida em que uma cultura pode receber ou rejeitar elementos de outras; as mudanças e trocas não existem baseadas numa relação causa/efeito, mas são sempre mediadas por interesses múltiplos.

Uma coletânea organizada por Appadurai (1986) afunila o conceito de cultura material sob a perspectiva das Ciências Sociais. Obra multidisciplinar e complexa que trata de temas como a mercadoria, a troca e os valores que são atribuídos aos objetos. Assuntos esses que são discutidos dentro de uma sociedade industrial avançada ou em sociedades tradicionais, cobrindo algumas sociedades orientais e ocidentais. Essa obra trata de desvendar o fetiche econômico do objeto quando inserido no circuito de troca, acrescentando que as imbricações econômicas passam pela Antropologia e a História. Os objetos devem, assim, ser estudados dentro de uma rede de significações e valores, para além de uma visão econômica, a fim de revelar seu valor concreto.

Porém, apesar da importância da cultura material para o entendimento de qualquer processo social, o conceito é ainda problemático no sentido de que sempre se priorizou o aspecto ideal da cultura em detrimento do seu aspecto material:

\begin{abstract}
Modern Western thought places a low value on material world and its products, paralleling traditional Christian morality: both are odds with modern Western capitalism, which places an inordinately high value upon the possession of material. This is one of the fundamental paradoxes of western life [...] Here we are concerned with the role Western philosophy has allotted to material culture, a role which can be described as subordinate or secondary, in which objects are seen as merely the outcome or the product - or even the detritus - of primary thinking, feeling and acting which is carried out elsewhere (PEARCE, 1994, p.17).
\end{abstract}

As pessoas se relacionam com os objetos e as coisas de formas diferentes. Num primeiro nível de forma direta, fazendo prevalecer o valor utilitário desses objetos. Num segundo nível, quando alguns objetos são feitos para agirem produzindo ou modificando outros objetos como é o caso dos instrumentos e das ferramentas. Um terceiro nível é possível quando vínculos com objetos são estabelecidos por caminhos indiretos, por mediações simbólicas, 
seja pela linguagem ou por imagens. E, por último, num quarto nível, o caso da acumulação, ou seja, o ato de colecionar objetos com a finalidade de sua simples posse ou exibição.

Este último aspecto, que diz respeito à relação dos os objetos com o fim de acumulação é nomeado de colecionismo. O fenômeno do colecionismo e das coleções emerge como um problema multidisciplinar. As coleções, num sentido mais amplo, chamaram a atenção de áreas como a Sociologia, por exemplo. Essa, contudo, ampliou seu escopo indo além da coleção para pensar o seu fundamento: o objeto. Dentro dessa linha, Baudrillard (1968) foi um dos primeiros a pensar o objeto, não isolado e descontextualizado, mas inserido na sua ambiência, ou seja, no ambiente que o rodeia, para logo passar a abordar seu aspecto econômico e social. Dentro da sociedade capitalista, pode-se dizer que o objeto do colecionismo torna-se, também, um objeto não unicamente de troca, mas de consumo. $\mathrm{O}$ autor chama a atenção para aspectos antes ignorados, como a retirada dos objetos dos sistemas sociais, para assim dar lugar aos repositórios de objetos e às coleções.

Todo objeto tem desta forma suas funções: uma que é a de ser utilizado, a outra a de ser possuído. A primeira depende do campo da totalização prática do mundo pelo individuo, a outra um empreendimento de totalização abstrata realizada pelo indivíduo sem a participação do mundo. Estas duas funções acham-se na razão inversa uma da outra. Em última instância o objeto estritamente prático toma um estatuto social: é uma máquina. Ao contrário, o objeto puro, privado de função ou abstraído de seu uso, toma um estatuto estritamente subjetivo: torna-se objeto de coleção (BAUDRILLARD, 1997, p.94).

Um dos trabalhos mais conhecidos sobre a história das coleções, em seu sentido mais estrito, foi realizado por Pomian (1982, p.67), que traça um aprofundado percurso das coleções desde as sociedades primitivas até o Século XVII, nelas identificando que os objetos têm um lado visível e um lado oculto.

Todas as coleções estudadas cumprem uma mesma função: a de permitir aos objetos que as compõem desempenhar o papel de intermediários entre os espectadores quaisquer que eles sejam - e os habitantes de um mundo aos quais aqueles são exteriores.

Pomian (1982, p.67) também destaca, na mesma seqüência, um aspecto importante das coleções no que se refere à quantidade de objetos necessários para que se forme uma coleção.

Mas quantos objetos são necessários para que exista uma coleção? É evidente que, em abstrato, uma tal questão não tem resposta [...] Porque, em geral, o número de objetos que formam a coleção depende do local em que se acumulam, do estado da sociedade, das suas técnicas e do modo de vida, de sua capacidade de produzir e 
acumular o excedente, da importância que se atribuía à comunicação entre o visível e o invisível por intermédio dos objetos.

Ainda dentro da história das coleções, o jornalista Philipp Blom (2003) constrói uma história das coleções onde enfatiza a relação entre coleção/colecionador. A obra inicia-se no Século XVI, discursando sobre um sábio humanista italiano cuja coleção está no limiar do gabinete de curiosidades. Ela se desenvolve pela exemplificação de uma coleção para cada época, mostrando uma série de problemas e questões éticas, culturais e sociais nesses percursos. Destaca, ainda, como as coleções refletem os avanços, preocupações e representações de um período específico da história; e, por último, recoloca a pergunta sobre o significado de uma coleção na época contemporânea, marcada pela produção em série e o consumo massivo e indiscriminado de bens.

Sob o prisma da Semiologia, o trabalho de Pearce (1992) problematiza e interpreta esses objetos nos seus contextos significativos. Para a autora, os objetos também são elementos significantes, sendo que diferentes significados podem ser atribuídos a eles, segundo a época de produção e de interpretação, e pelos lugares onde se encontram guardados ou estão sendo exibidos. Alguns lugares, como os museus, são capazes de se tornar ambientes nos quais os objetos possam ser ressignificados, não unicamente pelo fato de estarem em lugares que por si mesmos significam, mas também pelo arranjo (v.g. destaque de algum objeto) dentro do museu.

A autora também discute a questão da formação de coleções. Elas são os recolhimentos ou eleições que se fazem desses objetos por diferentes motivos, como veremos posteriormente, com a finalidade de serem possuídos ou expostos. Tem-se, assim, o lugar aonde se fecha o círculo, já que é no arranjo das coleções que esses significados dos objetos encontram sua vitalidade.

Collections, then, come about because individuals select objects and specimens out from the available material of the world, and put them together in a way which renders the meaning of the group more than the sum of its individual parts. The objects being materials, retain their link with the real world from which they come, but the collection is a metaphor for this reality, a dream, an inscription, on the world (PEARCE, 1992, p.66).

Nem todas as coleções pertencem eternamente ao seu criador - o colecionador. Com o tempo, grandes coleções formadas ao longo dos últimos quinhentos anos acabaram institucionalizando-se, quando não, acabaram desaparecendo. Por outro lado, muitas das 
coleções que sobreviveram, modificaram-se continuamente por vendas, heranças, etc., e passaram a fazer parte ou se constituíram elas mesmas em museus.

O exemplo disso é a obra pioneira de Bazin (s.d.), francês historiador da arte, quando traça um longo percurso dos museus, no sentido em que nos referimos anteriormente; e que acompanha, na sua totalidade, a história do Ocidente. A obra estende-se de Roma até a época contemporânea, centralizada nos grandes museus europeus e seus antecedentes nas coleções reais, aristocráticas ou eruditas, com ênfase nas coleções artísticas.

Obras recentes pretendem esclarecer o nascimento dos museus, como as de Hooper-Greehill (2003), para quem os museus e as coleções modernas aparecem com a finalidade de servir para a formação do conhecimento. No Renascimento, o cenário do colecionador é constituído por uma nova ordem econômica / social e um novo tipo de saber questionador / científico, e se traduz na figura do príncipe. Posteriormente, percebemos alterações no cenário devido a sucessivas mudanças, dando lugar às coleções museográficas criadas pelas sociedades reais, com um novo espírito científico e etnográfico, até chegarmos ao museu disciplinador contemporâneo, na visão da autora.

Isso significaria que, apesar de os museus cumprirem uma função aparente de entretenimento, lazer e diversão, eles também impõem condutas e silenciam acontecimentos e verdades. O museu, então, seria um lugar onde os objetos coletados seriam capazes de possuir variadas funções, criando assim, novos tipos de conhecimento.

\begin{abstract}
An 'effective' history has shown us how the meanings that are construed from objects are many, variable and fragile. Meanings are not constant, and the construction of meaning can always be undertaken again, in new contexts and with new functions. That radical potential of museums lies in precisely this. As long as museums and galleries remain the repositories of artifacts and specimens, new relationships can always be built, new interpretations with new relevancies can be found, new codes and new rules can be written (HOOPER-GREENHILL, 2003, p.215).
\end{abstract}

Um outro conceito moderno de museu nos é oferecido por Bennett (2005), que analisa diferentes aspectos sob a ótica de uma interpretação foucaultiana. Depois da apresentação sobre as origens dos museus, suas exibições e a racionalidade política sobre a qual se sustenta, o autor enfatiza o aspecto narrativo do museu através dos objetos.

Each museum type, then, is like a chapter within a longer story, pressing towards an end point which is simultaneously the point at which the next chapter commences. Like the reader in a detective novel, it is towards this end point that the visitor's activity is directed. This is not simply a matter of representation. To the contrary, for the visitor, reaching the point at which the museum's narratives culminate is a 
matter of doing as much as of seeing. The narrative machinery of the museum's 'back telling' took the form of an itinerary whose completion was experienced as a task requiring urgency and expedition (BENNETT, 2005, p.181).

Se, como visto, tem-se a temática das coleções e do colecionismo como objeto de investigação de natureza interdisciplinar - notadamente na Sociologia, História, História da Arte e Semiologia -, cabe agora investigar como essa temática é apropriada pelo universo da Museologia, área com a qual os estudos de coleção têm uma relação direta.

Com relação à Museologia, principalmente no que diz respeito à questão da formação de uma coleção, Pearce (1992) esclarece a relação entre coleção e colecionador. Para a autora, a relação se estabelece no ato da seleção, da busca; porém, as razões que levam a colecionar são obscuras, entretanto vitais. Estas razões fazem parte das características do ser humano, porque revelam as relações do homem com os objetos, de onde o colecionismo deve ser sempre levado a sério.

\begin{abstract}
Collections spring from existing individual and social constructions, but they also underwrite and perpetuate these constructs. Collections are endowed with a life of their own, which bears the most intimate relationship to that of their collector, so that the collectors see them, in the most literal sense, as part of himself. But at the heart of this relationship is an ambiguity of control; sometimes the collector shapes the collection and sometimes it shapes him - another way of saying that objects are always both active and passive. Collections are the artistic creation of self out of self, part of the connection of past and present and the hope of the future. Collectors who seek out what they love are involved in an effort of self-discovery and selfaffirmation which is characteristically human and so, no matter how trivial others may perceive the material to be, is itself never trivial (PEARCE, 1992, p.66).
\end{abstract}

A autora continua, afirmando que na sociedade capitalista contemporânea, o colecionismo é considerado como um divertimento, um hobby ou uma atividade de lazer, quando não lúdica. Decorrente desse fato, a competição entre colecionadores é bastante comum. O colecionismo é um ato voluntário que leva à construção de uma coleção, nunca pensada em partes, mas como um todo inseparável. As coleções sempre começam de forma espontânea, e, nesse sentido, elas existem pela vontade do colecionador, embora muitas delas sejam construídas como forma de prestígio social. Em muitos países, os colecionadores possuem meios de expressão e lugares de encontro para realizar suas atividades.

As coleções podem ser de diferentes tipos segundo a intenção do colecionador. Pearce (1992) destaca em primeiro lugar os souvenirs, cujo ato de colecionar é comum a quase todas as pessoas. Esse tipo de coleção pode ser constituído por todo tipo de objetos que só conseguem alguma unidade quando são associados à vida de uma pessoa ou de um grupo. No entanto, podem chegar a um museu quando, dependendo daquilo que possam dizer sobre uma época 
ou uma pessoa, outras informações possam ser deduzidas. Em segundo lugar, e diferentemente dos souvenirs, o fundamento das aqui chamadas coleções fetichistas recai não nos objetos, mas no sujeito colecionador. A diferença entre essas duas intencionalidades é muito tênue, porque ambas se fundamentam num processo irracional, pelo qual se estabelecem relações afetivas entre o colecionador e seus objetos. Mas no caso dos souvenirs tem-se a formação de um outro universo, construído a partir da retirada do objeto de uma rede de relações, na qual ele poderia ter existido de maneira diferente. Em terceiro lugar, têm-se as coleções sistemáticas, que aparecem no Renascimento, e se constituem racionalmente segundo um princípio que articula, sob uma ou várias categorias, os objetos colecionados.

\section{A BIBLIOTECONOMIA E AS COLEÇÕES BIBLIOGRÁFICAS}

Este aspecto diz respeito à abordagem com que a Biblioteconomia se aproximou dos estudos de coleções. Assim, num primeiro momento, a Biblioteconomia esteve mais atenta às bibliografias (aqui entendidas como repertórios de acesso à informação) do que às coleções propriamente ditas. Posteriormente, sua preocupação se centrou na organização das coleções de livros e no uso que delas se poderia fazer, motivo pelo qual foi em busca das necessidades dos seus usuários.

Nas últimas décadas, porém, a Biblioteconomia voltou seu olhar para os estudos de desenvolvimento de coleções, seguindo as tendências dos estudos de planejamento e administração (VERGUEIRO, 1989). Munidos de um embasamento vindo da Administração, os estudos da Biblioteconomia sobre coleções se dedicaram ao planejamento do seu desenvolvimento. Nesse contexto, aperfeiçoaram-se os modelos, métodos e técnicas para se prever o crescimento de uma determinada coleção, entre eles os métodos vindos dos estudos de usuários e da bibliometria, insistindo-se na necessidade de os bibliotecários terem clareza dos seus objetivos, para que seus acervos não fossem um apanhado de documentos sem ordem nem conserto (ANDRADE; VERGUEIRO, 1996).

O estabelecimento de critérios para saber onde e como alocar as verbas sempre exíguas também foi uma preocupação desses estudos, assim como os problemas de consciência dos profissionais no momento da seleção e do descarte (evitando possíveis interferências pessoais na escolha dos itens). 
A Biblioteconomia, quando incorporou as reflexões e estudos vindos da Administração especialmente da administração de empresas -, privilegiou as bibliotecas empresariais. Desse modo, as regras de produtividade, no menor custo e tempo possível, se tornaram a norma, dando lugar para que as bibliotecas se tornassem lugares frios e impessoais. Isso significou que o interesse da Biblioteconomia girasse quase que exclusivamente em torno das bibliotecas institucionais, negligenciando-se as bibliotecas particulares.

Decorrente dessa influência da Administração, as coleções bibliográficas foram estudadas de forma a-histórica, como se elas sempre tivessem existido dessa forma, esquecendo suas origens e seus percursos. Interessante que, para conceber os objetivos de uma biblioteca, de um museu e mesmo da política de suas coleções necessitamos saber, antes, como essas coleções se formaram. Pois é exatamente a dinâmica dessas coleções que imprimem seus objetivos e suas políticas. Assim, a Biblioteconomia se interessou em menor escala pela formação das coleções, sem perceber que é justamente o motivo que leva alguém a colecionar que, posteriormente, determinará os objetivos da coleção.

Já o fenômeno do colecionismo adquire dinâmicas diferentes quando adentramos o mundo dos livros. Se, anteriormente, afirmamos que a Biblioteconomia tinha desviado seu olhar dos livros para a gestão do seu crescimento, isto é, no que diz respeito às coleções, desde sempre, na nossa área, existiu a curiosidade - hoje relegada - sobre o impulso de colecionar de livros. Na relação da Biblioteconomia a respeito da coleção de livros, um campo mais restrito aparece com os estudos de Bibliofilia. Uma obra pioneira no país sobre esse fenômeno foi publicada em 1965 por Rubens Borba de Moraes (1998), intitulada O bibliófilo aprendiz. Como o título menciona, a obra pretende narrar a experiência pessoal de um colecionador de livros, suas preferências, os sebos, as emoções, os truques, etc., sendo que ao mesmo tempo, pode servir de guia para futuros colecionadores.

Autor erudito e profundo conhecedor da bibliografia nacional, Rubens Borba de Moraes teve grande trânsito por importantes bibliotecas (seja como freqüentador ou como diretor) e na referida obra demonstra sua familiaridade com os livros, evidenciando um profundo conhecimento tanto no aspecto editorial como nos conteúdos dos textos nacionais.

Desse modo, sua obra pode ser considerada um marco importante do tema: colecionismo de livros. Ainda, além das sugestões e conselhos, esta obra, como outras do gênero, oferece deliciosas passagens da vida do autor e sua relação com os livros, aspecto tão pouco estudado hoje em dia em nossa área. 
No campo mais restrito da bibliofilia, os trabalhos costumam ser jocosos, inventivos, bemhumorados e inteligentes, quando não livros cheios de reminiscências e lembranças, às vezes até nostálgicas. Como vimos, na obra de Rubens Borba de Moraes, esse gênero literário transita pelo manual e pela autobiografia. Já a obra de Raabe (2001) constitui um bom exemplo de livro humorístico. Embora fortemente enraizado em uma realidade totalmente diferente da nossa (sociedade americana), ela serve para se ter uma idéia de como o tema pode e está sendo desenvolvido em outras realidades.

Merecem destaque algumas definições que o autor dá para fenômenos correlatos em relação aos livros, quando por exemplo, define e diferencia termos como: readholics, bibliowebbies, bibliopaths, bibliocasts e bibliophagi. Também oferece exemplos de reações psicossomáticas de colecionadores frente a um item desejado, entre outros.

Dentro da ambigüidade do gênero, Schwartz (1996) transita não unicamente pelo humor e a biografia, mas também pela literatura e os hábitos de leitura. A narração é contínua, não separada por capítulos. Inicia-se com o diálogo de um sacerdote zen que pede para interromper a leitura e a autora argumenta baseada na literatura universal que a leitura continue. A partir desse dispositivo, a autora entrelaça seus argumentos sobre a paixão pelos livros e o afã para colecioná-los.

Basbanes (1995) apresenta um exaustivo, erudito e singular trabalho, que cobre e contextualiza a história em cada um dos aspectos da bibliofilia. Embora circunscrito basicamente aos Estados Unidos da América e à Inglaterra, esse livro emerge como uma obra que vale também pelo seu aspecto metodológico, sobretudo para quem queira fazer uma história da paixão pelos livros.

\section{PARA ALÉM DA INFORMAÇÃO, O OBJETO LIVRO}

O aparecimento da Ciência da Informação algumas décadas atrás, priorizou a construção do seu objeto a partir da informação. Informação no sentido de momento intermediário entre o dado e o conhecimento, de forma que pudesse ser quantificável, manipulável, fabricada; ignorando dessa forma a materialidade dos suportes nos quais a informação estava registrada. Com a configuração da Ciência da Informação como área de conhecimento, a informação levou ao esquecimento da biblioteca (a informação pode estar ou não na biblioteca), ou seja, a 
institucionalidade de um espaço físico denominado 'biblioteca' com práticas e saberes específicos passa a se esconder na virtualidade da informação.

A Ciência da Informação pode ser considerada uma disciplina que tem como objeto de estudo a informação registrada em documentos propositalmente criados para transmiti-la ou armazená-la, e que são tratados em lugares como as bibliotecas e os arquivos. Num sentido mais amplo, a informação se encontra também em objetos que ficam aos cuidados dos museus. Essa visão aponta, por um lado, para a relação entre a Biblioteconomia e a Arquivologia (documentos feitos propositalmente para informar) e, por outro lado, relega à Museologia (objetos cujo valor informativo é extrínseco). Uma visão conciliadora vinda de estudiosos recentes da Ciência da Informação (SMIT, 2000) tratou de achar um lugar comum, ou em outras palavras, uma base epistemológica para essas instituições, ampliando o conceito de informação.

Durante as primeiras décadas dessa área ainda em construção, a Teoria da Informação ofereceu os subsídios teóricos para sua consolidação, esquecendo dessa forma a Documentação, que a partir de outras vertentes, também, continuou desenvolvendo suas práticas e teorias para o trabalho documental. Assim, hoje podemos por fim presenciar uma aproximação entre a Ciência da Informação e a Documentação, quando se resgata o conceito de informação como coisa - recuperando o aspecto tangível e material da informação (BUCKLAND, 1991).

Acreditamos que a razão do predomínio da informação imaterial resida no fato de se ter tradicionalmente destacado a informação em si, não na materialidade do documento nem na historicidade das instituições com as quais se lida. Em decorrência, foram criados Centros ou Unidades de Informação, como uma adaptação dos arcaicos Arquivos, Bibliotecas e Museus, nos tempos das tecnologias e dos saberes especializados. No entanto, como recorda Homulos (1990), são todas pertencentes a uma mesma família das "instituições coletoras de cultura", isto é, a informação foi entendida como um ente imaterial, ao invés de colocá-lo na práxis, na atividade, na profissão de cada uma dessas instituições a respeito dos seus documentos.

Entende-se por instituições coletoras de informação e cultura os espaços responsáveis pelo armazenamento, tratamento, organização, divulgação e disseminação da informação, cujas funções são baseadas na educação, cultura e lazer. Além de tais funções, essas instituições objetivam preservar seus acervos, de modo a determinar o que pode vir a tornar-se ou não conhecimento. 
Assim, apontamos a necessidade de considerar as coleções (suas origens e percursos) como um elemento que sirva como uma base epistemológica às instituições "coletoras de cultura" (bibliotecas e museus), pois nelas se revelam, por um lado, os saberes e os fazeres próprios de cada instituição; e por outro, as práticas e representações sociais nas quais elas estão arraigadas.

Focalizando a questão das instituições coletoras de cultura nas bibliotecas e suas relações com a informação, Baratin e Jacob (2000, p.10), numa perspectiva contemporânea, conceituam a biblioteca como:

\begin{abstract}
Um lugar, uma instituição. É o cruzamento paradoxal de um projeto utópico (fazer coexistir no mesmo espaço todos os vestígios do pensamento humano confiados à escrita) com as restrições técnicas, ergonômicas, políticas de conservação, de seleção, de classificação e de comunicação dos textos, das imagens e, hoje, dos sons. É também, e simultaneamente um desígnio intelectual, um projeto, um conceito imaterial que dá sentido e profundidade às práticas de leitura, escrita e de interpretação.
\end{abstract}

Latour (2000, p.21) amplia o sentido atribuído à biblioteca. Ele não a considera uma fortaleza isolada ou um espaço fechado a possíveis contribuições, mas insere-a em uma vasta rede, onde matérias tornam-se signos e essas transformações podem circular de maneira constante. A construção de uma rede de transformações entre laboratórios, coleções e bibliotecas fazem com que atuem como verdadeiros laboratórios, dando lugar a um deslocamento das propriedades dos fenômenos, redistribui o espaço-tempo e proporciona aos "capitalizadores" uma vantagem, pois "[...] uma vez que eles estão ao mesmo tempo afastados dos lugares, ligados aos fenômenos por uma série reversível de transformações, e aproveitam o suplemento de informações oferecido por toda e qualquer inscrição a todas as outras" (LATOUR, 2000, p.37). Esses lugares, por sua vez, ligam-se por muitas vias ao mundo, de forma a transformarem dimensões e propriedades inerentes.

Para o autor, a biblioteca, para que ela possa ser considerada um laboratório, não pode somente acumular milhões de signos e permanecer isolada, mas se integrar nessa rede, pois os fenômenos circulam através dela e sua circulação permite verificá-los, assegurá-los e validálos.

Restaria, no entanto, um outro destaque que consideraria a biblioteca como um espaço físico evocador de lembranças e simbolicamente como elemento fundamental de criação de identidades, sejam individuais ou coletivas. Tomado sob a presente perspectiva, Meneses (1994) analisa a importância dos espaços físicos institucionais, como lugares que desempenham a função de evocação, celebração e enculturação da memória de personagens e 
grupos retratados, denominando-os, assim, de Teatro da Memória. Porém, os espaços institucionais, além de se configurarem sob o aspecto do espetáculo que evoca e celebra também se delineiam como um espaço de trabalho sobre a memória, em que é tratado como objeto gerador de conhecimento. Assim, uma biblioteca pode ser um Teatro, mas também pode ser um Laboratório, porque ela traduz a vida pessoal e institucional de seu coletor, seja individual ou institucional.

Sendo um lugar que procura estabelecer o pertencimento e reconhecimento, faz-se necessário enfatizar a questão da cultura material na biblioteca, questão que é importante, uma vez que a materialidade, como condição do saber institucionalizado na letra, é necessária no momento no qual o acervo é tomado como um instrumento para a compreensão. Essa discussão nos leva ao entendimento de que não existem bibliotecas sem livros. Tomados por seu caráter material e inseridos em um espaço institucional, os elementos intrínsecos dos mesmos são incorporados pelas instituições responsáveis pelo trabalho de reconstrução da memória e identidade de grupos ou indivíduos (no caso, a biblioteca), de modo que exerçam um controle dos possíveis significados inerentes aos objetos e assim operacionalizem uma relação de cruzamento entre o caráter pessoal e o contexto público.

Gostaríamos de apresentar uma proposta que considera o livro a partir do aspecto da materialidade do seu suporte e desde a perspectiva do texto. Isto é, uma abordagem que permite estabelecer as relações que o sujeito mantém com o livro, incluindo o seu colecionismo.

\begin{abstract}
A obra literária [informação] é, pois, um objeto invisível, o livro um objeto visível. Esta diferença do estatuto ontológico tem por conseqüência vários outros. A obra literária [informação] é invariante em relação às suas realizações físicas, se só existir entre elas uma correspondência biunívoca; pode-se recitá-la, escrevê-la, numerá-la, continua a ser a mesma. É invariante em relação às suas realizações psíquicas, e é por isso que, sendo tão numerosa como seus leitores, estes podem, falando a seu respeito, falar de uma mesma obra, conquanto que disponham das competências que lhes permitam compreendê-la. E é invariante finalmente em relação às suas relações lingüísticas, o que torna possível as traduções [...] A obra literária [informação] existe fora do tempo e do espaço, pois, sempre e em toda parte, ela conserva-se idêntica a si mesma. Neste sentido é uma entidade ideal. O livro, como objeto visível, mas também tátil, existe evidentemente no tempo e no espaço: ocupa lugar, pesa, muda (POMIAN, 1998, p.72).
\end{abstract}

Esta proposta de Pomian configura-se interessante por dividir as abordagens humanísticas em dois grandes campos. No entanto, revela-se determinista quando assinala que elas nunca deveriam mesclar-se, que elas se excluem. Colocamos essa citação de Pomian para mostrar a necessidade de resgatar uma abordagem que privilegie o suporte, sua materialidade, vale dizer 
uma ontologia fundamentada num lugar preciso no espaço e no tempo, aliás, passível de agir nesse cruzamento apriorístico. Respaldado por tal visão, buscamos fundamentar o trabalho por essa abordagem pragmática, entendendo ser necessário repetir que servirá fundamentalmente como ponto de partida, já que no caso de informação e seu suporte essas duas categorias são inseparáveis.

Esse enfoque do livro emerge a partir de um novo conceito, para uma melhor compreensão da importância da cultura material e o livro, e para os estudos de coleções bibliográficas. Essa idéia foi formulada por Pomian (1998) acerca dos semióforos.

Como o próprio autor comenta que longe de querer criar mais um neologismo, ele pretende resgatar algumas categorias classificatórias que elucidem o panorama dos objetos e sua inserção na cultura. Para isso, divide os objetos entre aqueles criados pela natureza e os criados pelo ser humano, esclarecendo que nos objetos humanos existem sempre um destino e um emprego, ao passo que nos naturais há, unicamente, o emprego ou não deles. Em ambos os tipos, a utilização ou não deles dá lugar a outras duas categorias: os corpos - quando esses objetos são empregados; e os restos, quando não se usam mais. Entre os corpos e os restos existe uma gama de outros objetos definidos pelo seu destino e pelo seu emprego, entre eles, as coisas (objetos que dão lugar a outros objetos. v.g. ferramentas) e os semióforos.

Continuando, Pomian identifica, ainda, vários tipos de semióforos: a) os textos, os quais são homogêneos pelos seus signos e diversos pelos seus formatos - livros, jornais, partituras, placas com nomes de ruas, manuscritos e escritos à máquina, rótulos, etc. Eles conservam ainda elementos do passado, dos vestígios; b) as imagens - desenhos, quadros, estampas, fotografias, mapas, maquetes, instalações etc. Neles nem os signos, nem os suportes são os mesmos. As imagens, ao invés da escrita, não possuem um repertório, nem um código uniforme; c) os comandos, diferentemente dos anteriores, não estão voltados para o passado, mas nos remetem para o futuro - notas de banco, moedas; também podem ser ícones que nos permitem ou proíbem uma ação; d) os expósitos, objetos feitos para serem expostos, ou adquiriram essa qualidade posteriormente. Nesse sentido, "qualquer objeto se transforma em semióforo em conseqüência da descontextualização e da exposição. E é-o durante tanto tempo quanto estiver exposto" (POMIAN, 1998, p.85). Mas, em última instância, o que seria um semióforo? Para responder a essa pergunta, o autor coloca como exemplo de semióforo por excelência, o livro. 
livro só conserva quando se adota face a ele uma das atitudes programadas pela sua própria forma: quando o lemos ou o folheamos, ou pelo menos, quando o colocamos nas prateleiras da nossa biblioteca, de uma livraria, de uma loja de alfarrabista. Trata-o também como semióforo aquele que o preserva por ver nele um livro, sem no entanto estar disposto a lê-lo, ou que só vê nele um objeto estranho ou precioso que, por essa razão, resolve guardar. E aquele que o manda queimar convencido de que pode exercer uma influência nociva sobre os leitores ou por querer destruir as produções escritas de um grupo, com o fim de destruir esse mesmo grupo (POMIAN, 1998, p.77).

Portanto, quando consideramos o livro como semióforo, ele pode sê-lo de dois tipos e ao mesmo tempo: textual e expósito, qualidade esta que o equipara a qualquer objeto museológico e que o aproxima da cultura material. Por isso, o livro pode como qualquer outro objeto, ser passível de ser colecionado. Assim, ao livro como a qualquer outro objeto, tanto no momento de seu recolhimento, como no momento de sua disposição e/ou exposição (pública ou privada), podem ser-lhe atribuídos alguns valores, sejam eles afetivos, utilitários, emblemáticos, etc.

Pomian (1998) menciona que, desde o início do Século XX, existem nas Ciências Humanas, duas abordagens denominadas como: abordagem semiótica e abordagem pragmática. Nesse trabalho, ele coloca como exemplo os estudos literários, diferenciando a abordagem preocupada com o texto (semiótica) e a outra, preocupada com o livro suporte (pragmática). Essas diferenças se enquadram tranqüilamente na Ciência da Informação se mudarmos texto por informação, colocando o livro como semióforo.

Enquanto objeto, o livro é "inseparável de sua forma física" (POMIAN, 1998, p.73), ele não é somente um suporte de informações, mas também um portador de significados externos, e configura-se como objeto visível, investido de significados. Esses objetos, Pomian (1998, p.77) define como semióforos. Ainda para o autor, o semióforo é composto por dois elementos: um suporte e signos e, são "[...] destinados a substituir, completar ou prolongar uma troca de palavras, ou a conservar-lhe o vestígio, tornando visível e estável o que de outra forma ficaria evanescente e acessível unicamente ao olvido" (POMIAN, 1998, p.80), ou seja, o semióforo existe para ser olhado e interpretado.

Pomian (1998, p.85) considera que "qualquer objeto se transforma em semióforo em conseqüência da descontextualização e da exposição. E, o é durante tanto tempo quando estiver exposto". Tal fato deve-se a essa exposição acontecer de forma a proteger o objeto com algum elemento físico (como ocorre nos museus), de modo que os mesmos sejam olhados, contemplados, tal atitude resulta em uma modificação no espectador, "[...] pois trazlhe alguma coisa de que de outro modo ficaria desprovido" (POMIAN, 1998, p.85). 
Dessa forma o livro perde o seu valor informativo para tornar-se um símbolo - quando ele é um semióforo -, sendo que seu sentido faz-se necessário para a proposta desta reflexão, uma vez que esses objetos inseridos na biblioteca permitem estabelecer a construção de um espaço evocativo, comemorativo ou recordatório de seu coletor.

\section{CONCLUSÃO}

Decorrente da emergência das coleções e do colecionismo de livros como temas de estudo desta pesquisa, ainda resta por saber: numa sociedade onde as bibliotecas e os meios de informação são cada vez mais presentes, quais seriam os motivos para colecionar livros? Se comparado com o colecionismo de quaisquer outros objetos, o que diferencia a coleção de livros? Qual seria a relação entre o livro como meio de informação e seus dispositivos simbólicos e subjetivos no momento de sua coleção?

Acreditamos que para responder a essas perguntas devemos priorizar o fato de que, além do texto (informação), dos significados e da utilidade informativa, existem no livro características determinadas pelo seu suporte, pelos valores a ele atribuídos como símbolo social, como fetiche ou como lugar da memória, que acionam certos dispositivos subjetivos e pessoais que levam a sua posse e coleção. Além do que, somente identificando as origens das coleções, poderemos posteriormente mantê-las e administrá-las. Resta saber a maneira pela qual, no mundo da cultura material, apresentando características próprias, o livro possa apresentar uma dinâmica singular na atividade do colecionismo como mediador entre o sujeito e a realidade.

\section{REFERÊNCIAS}

ANDRADE, D.; VERGUEIRO, W. Aquisição de materiais de informação. Brasília: Briquet de Lemos, 1996.

APPADURAI, A. (Org.). The social life of things. Cambridge: Cambridge University Press, 1986. 
BASBANES, N. A. A gentle madness: bibliophiles, bibliomanes, and the eternal passion for books. New York: Henry Holt and Company, 1995.

BAUDRILLARD, J. O sistema dos objetos. São Paulo: Perspectiva, 1997.

BAZIN, G. El tiempo de los museos. Madrid: Daimon, [s.d.].

BENNETT, T. The birth of the museum: history, theory and politics. London: Routledge, 2005.

BLOM, P. To have and to hold: an intimate history of collectors and collecting. New York: The Overlook Press, 2003.

BUCAILLE, R.; PESEZ, J. M. Cultura material. In: ROMANO, R. Enciclopédia Einaudi: Homo/Domesticação. Lisboa: Imprensa Casa da Moeda, 1989. v. 16; p.11-47.

BUCKLAND, M. K. Information as thing. Journal of the American Society for Information Science, v.45, n.5, p.351-360, 1991.

HOMULUS, P. Museums to libraries: a family as collecting institutions. Art Library Journal, v.15, n.1, p.11-13, 1990.

HOOPER-GREENHILL, E. Museums and the shaping of knowledge. London: Routledge, 2003.

JACOB, C. Prefácio. In: BARANTIN, M.; JACOB, C. O poder das bibliotecas: a memória dos livros no Ocidente. Rio de Janeiro: Editora da UFRJ, 2000. p.9-17.

LATOUR, B. Redes que as bibliotecas desconhecem: laboratórios, bibliotecas, coleções. In: BARATIN, M.; JACOB, C. O poder das bibliotecas: a memória dos livros no Ocidente. Rio de Janeiro: Editora da UFRJ, 2000. p.21-44.

MENESES, U. T. B. de. Do teatro da memória ao laboratório da História: a exposição museológica e o conhecimento histórico. Anais do Museu Paulista, v.2, p.9-42, jan./dez. 1994.

PEARCE, S. M. Museums, objects and collections: a cultural study. Washington: Smithsonian Institution Press, 1992. 
. (Ed.). Interpreting objects and collections. London: Routledge, 1994.

POMIAN, K. Colecção. In: ROMANO, R. Enciclopédia Einaudi: Memória/História. Lisboa: Imprensa Casa da Moeda, 1982. v.1; p.51-85.

. História cultural, história dos semióforos. In: RIOUX, J. P.; SIRINELLI, J. F.

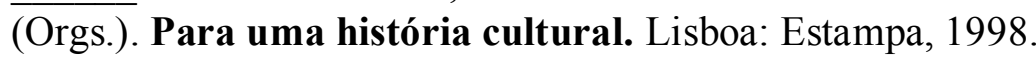

RAABE, T. Biblioholism: the literary addiction. Golden: Fulcurm Publishing, 2001.

SCHWARTZ, L. S. Ruined by reading. Boston: Beacon Press, 1996.

SMIT, J. W. Arquivologia, Biblioteconomia e Museologia - O que agrega estas atividades profissionais e o que as separa? Revista Brasileira de Biblioteconomia e Documentação, São Paulo, Nova Série, v.1, n.2, p.27-36, 2000.

VERGUEIRO, W. Desenvolvimento de coleções. São Paulo: Editora Polis: APB, 1989.

\begin{abstract}
This work explores an often forgotten subject by librarianship: the birth of bibliographic collection. Since beginning, Information Science's focus has been on information, and, as a result, the material support has taken a second place. In order to initiate a discussion that attempts to rescue the information support, without loosing information, it is proposed the concept of semióforo as a way to overcome the division between material/immaterial. The paper is divided into three parts: the first one displays a bibliographic review in order to introduce concepts as Material Culture and Collecting, in different fields. In the second one, the discussion is delimited by the field of Librarianship, looking for its relationship with bibliographic collections, placing emphasis on Bibliophile. Finally, the work's title emerges by pointing out the lack of bibliographic collection studies in the field of Library Sciences. It also proposes the use of semióforo concept not only to deal with the division support/text, but one that provides theoretical subsidies to work out the problem offering subsidies for the field of theoretical discussion. Then, it is supposed to reach the main goal of the project: to discus that, as an object, the book has some characteristics features, some of them subjectivists and materialistics which determine that the individual could be capable to establish some kind of relations that of the simple search of information.
\end{abstract}

Keywords: Collections. Bibliographical collecting. Books.

Originais recebidos em: 05 de março de 2009

Aceitos para publicação em: 14 de maio de 2009 